\title{
Filling a Significant Gap in the Cardiac Intensive Care Unit (CICU): Quality Improvement Using the Newborn Individualized Developmental Care and Assessment Program (NIDCAP) Approach
}

\author{
Butler S1, Hartwell L2, Thornton J2, LaRonde $\mathrm{M}^{2}$, Rachwal $\mathrm{C}^{2}$ \\ 1 Psychiatry, Boston Children's Hospital, Boston, MA USA \\ ${ }^{2}$ Cardiology, Boston Children's Hospital, Boston, MA USA
}

\section{Aims}

Congenital heart disease (CHD) is among the most common birth defect with approximately 36,000 U.S. infants born annually. ${ }^{1,2}$ More than one-third of infants with CHD will require infant surgery. ${ }^{3,4}$ Neurodevelopmental disabilities are the most common, and arguably the most distressing, long-term morbidity in survivors. ${ }^{1,2,5}$ While mortality rates for children with CHD have significantly declined, neurologic abnormality and neurodevelopmental impairment have increased. Neurodevelopmental deficits are noted from infancy to adulthood including developmental delays, learning disabilities, social and emotional concerns and behavioral problems. ${ }^{6-10}$

There are many causes of the neurodevelopmental concerns in individuals with CHD. One modifiable cause is the in-hospital care and its negative effects on the developing newborn brain. The cardiac intensive care unit (CICU), while necessary to save the life of the infant with CHD, exposes infants to overwhelming stress through noxious stimuli, including painful procedures, invasive lines and tubes, toxic sensory stimulation, and separation from family. Current research advocates for adjustment to medical practice to reduce the detrimental developmental effects. ${ }^{11,12}$ Research also indicates that interventions such as developmental care (DC) are minimal in cardiology due to a need for staff education and a shortage of evidence for the benefits of DC in cardiology. ${ }^{13}$

Individualized DC in the NIDCAP approach ${ }^{14}$ attempts to minimizes the mismatch between infant neurobiological needs and the CICU environment, thus diminishing the frequency and severity of adverse effects on the infant with CHD. NIDCAP has repeatedly proven to improve neurodevelopment and psychosocial outcomes for high-risk infants and their families. ${ }^{15-17}$ The global aim of the current project was to be the first CICU to implement and measure NIDCAP care.

\section{Methods}

An interdisciplinary team was convened to implement NIDCAP care in the CICU through quality improvement (QI). Developmental care implementation included: (1) staff education, (2) child neurodevelopment assessment and intervention, (3) clinician support, (4) family support, and (5) QI measurement methodology. Current care practice was evaluated using the NIDCAP Nursery Environment and Care Component Template Manual ${ }^{18}$ (Templates) along with additional questions on infant holding and family participation taken from the NIDCAP Nursery
Certification Criterion Scales. ${ }^{19} \mathrm{~A}$ five point rating scale ( $1=$ traditional care to $5=$ highly attuned NIDCAP implementation) was used. Thirty CICU nurses were trained in the basics of NIDCAP and served as champions in the CICU. Seven were additionally trained and reliable on use of the Templates $(>90 \%)$. Background medical data was also collected. The impact of developmental care implementation was monitored through statistical process control methodology ${ }^{20}$ to observe changes in care prior to, during, and after NIDCAP implementation. Plan-Do-Study Act (PDSA) methodology was used to refine the process and intensify practice change.

\section{Results}

Over two years of intervention implementation, there have been no major adverse events related to NIDCAP care. Template data was measured quarterly (77 templates, ongoing collection). Evidence for significant improvement in mean scores from below the lower control limit to above the upper control limit was noted in bedding and clothing; supports for infant selfregulation; position, movement and tone; timing and sequencing of caregiving; and family participation. (Figure 1) Slight improvement was noted in environment and infant holding. Results led to an individual task force to support environmental change, additional professionals recruited to DC team, and supplementary staff education provided.

\section{Conclusion}

This QI study evaluates the efficacy of NIDCAP in the CICU for newborns with CHD. Evidence for significant improvement in mean scores of DC was noted in infant and family support. NIDCAP care efforts showed meaningful improvement in the CICU through education and staff support with ongoing need for QI science. Our increased performance of developmental care is likely related to current QI efforts and dedicated developmental care team.

References:

1. Loffredo CA. Epidemiology of cardiovascular malformations: prevalence and risk factors. American Journal of Medical Genetics 2000,97(4):319-325.

2. Fyler DC. Report of the New England regional infant cardiac program. Pediatrics 1980,65:377-461.

3. Mahle WT, Spray TL, Wernovsky G, Gaynor JW, Clark BJ. Survival after reconstructive surgery for hypoplastic left heart syndrome: a 15-year experience from a single institution. Circulation 2000,102(suppl 3):Iii-136-Iii-141.

4. Jacobs JP, Quintessenza JA, Burke RP, et al. Analysis of regional congenital cardiac surgical outcomes in Florida using the Society of Thoracic Surgeons Congenital Heart Surgery Database. Cardiol Young 2009,19(04):360-369. 
The solid center line represents the average score for the entire time period (CY 2017 Q3-2019 Q2). The dashed lines represent upper and lower control limits, which correspond to $\pm 3 \sigma$ from the center line. Special cause is indicated by the red square dots above the center line, which suggest significant improvement in mean scores.
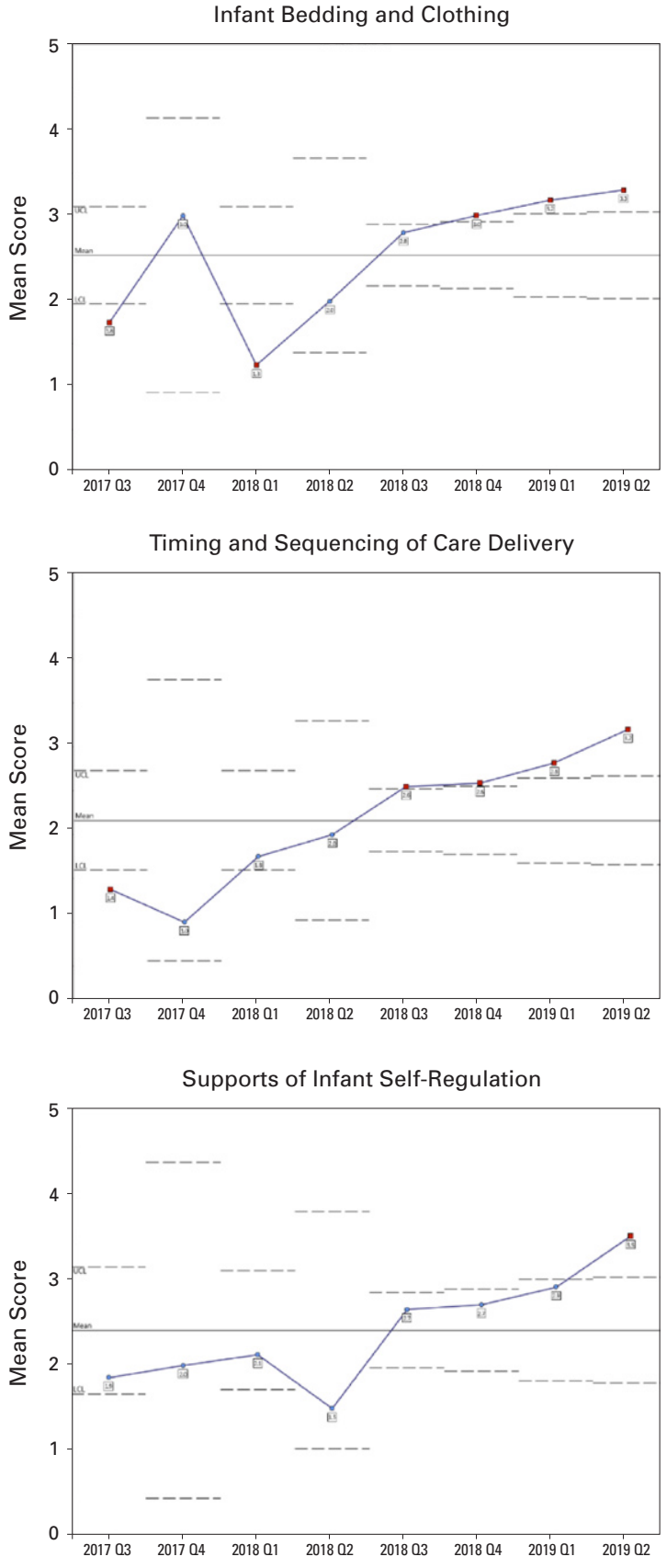

5. Ferry PC. Neurologic sequelae of cardiac surgery in children. American Journal of Diseases of Children 1987,141(3):309-312.

6. Marino BS, Lipkin PH, Newburger JW, et al. Neurodevelopmental outcomes in children with congenital heart disease: evaluation and management: a scientific statement from the American Heart Association. Circulation 2012,126(9):1143-1172.

7. Mussatto KA, Hoffmann RG, Hoffman GM, et al. Risk and prevalence of developmental delay in young children with congenital heart disease. Pediatrics 2014,133(3):e570-e577.

8. Marino B S, P.H. L, J.W. N, al. e. Neurodevelopmental outcomes in children with congenital heart disease: Evaluation and management: A scientific statement from the American Heart Association. Circulation 2012,126:1143-1172.

9. Wernovsky G. Current insights regarding neurological and developmental abnormalities in children and young adults with complex congenital cardiac disease. Cardiology in the Young 2006,16(S1):92-104.
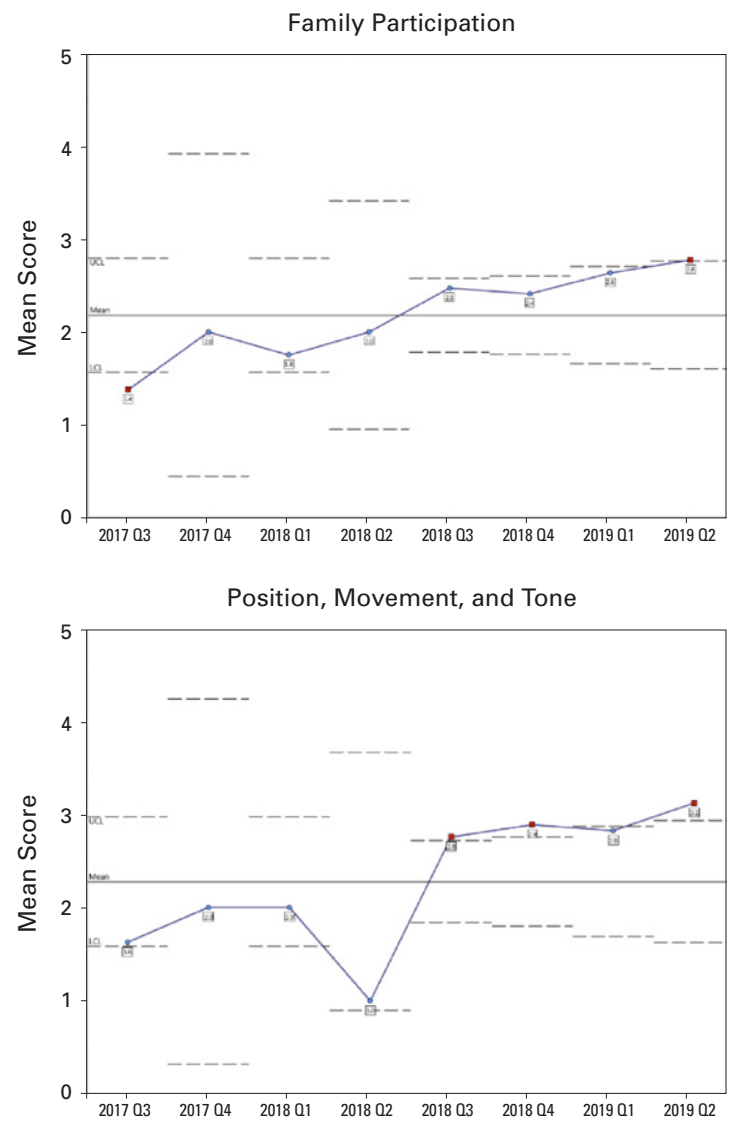

10. Snookes SH, Gunn JK, Eldridge BJ, et al. A systematic review of motor and cognitive outcomes after early surgery for congenital heart disease. Pediatrics 2010,125(4):e818-e827.

11. Lisanti AJ, Vittner D, Medoff-Cooper B, Fogel J, Wernovsky G, Butler S. Individualized family-centered developmental care: An essential model to address the unique needs of infants with congenital heart disease. Journal of Cardiovascular Nursing 2019,34(1):85-93.

12. Daniels JM, Harrison TM. A case study of the environmental experience of a hospitalized newborn infant with complex congenital heart disease. The Journal of cardiovascular nursing 2015 .

13. Sood E, Berends WM, Butcher JL, et al. Developmental care in north american pediatric cardiac intensive care uUnits: Survey of current practices. Advances in Neonatal Care 2016,16(3):211-219.

14. Als H. Manual for the naturalistic observation of the newborn (preterm and fullterm): Children's Hospital, Boston, Mass. Copyright, NIDCAP Federation International, 2006,1981 rev. 1995.

15. Als H, Duffy F, McAnulty GB, et al. Early experience alters brain function and structure. Pediatrics 2004,113(4):846-857.

16. Als H, Duffy FH, McAnulty G, et al. NIDCAP improves brain function and structure in preterm infants with severe intrauterine growth restriction. J Perinatol 2012,32:797-803.

17. Kleberg A, Westrup B, Stjernqvist K. Developmental outcome, child behaviour and motherchild interaction at 3 years of age following Newborn Individualized Developmental Care and Intervention Program (NIDCAP) intervention. Early Human Development 2000,60(2):123135.

18. Als H, Buehler D, Kerr D, Feinberg E, Gilkerson L. Profile of the nursery environment and of care components. Template Manual, Part I. Boston: Children's Hospital; 1990, 1995. Rev. 1997.

19. Smith K, Buehler D, Als H. NIDCAP Nursery Certification Criterion Scales. Boston: Copyright, NIDCAP Federation International;2009.

20. Wheeler DJ. Understanding variation. The Key to Managing. 1993. 